\title{
Relationship Between Initial Parenteral Iron Therapy Dosing and Treatment Effectiveness: A Real-World Retrospective Analysis
}

\author{
Chris LaVallee (1) ', Isha Bansal ${ }^{2}$, Shilpa Kamdar ${ }^{2}$, Winghan Jacqueline Kwong ${ }^{3}$, Ralph V Boccia ${ }^{4}$ \\ 'Health Outcomes Research, Decision Resources Group, Burlington, MA, USA; ${ }^{2}$ Analytics, Decision Resources Group, Burlington, MA, USA; ${ }^{3}$ Health \\ Economics \& Outcomes Research, Daiichi Sankyo Inc., Basking Ridge, NJ, USA; ${ }^{4}$ Center for Cancer and Blood Disorders, P.C, Bethesda, MD, USA
}

Correspondence: Winghan Jacqueline Kwong, Daiichi Sankyo, Inc., 21 I Mt Airy Road, Basking Ridge, NJ, 07920, USA, Tel +I 9089927063 ,

Email jkwong@dsi.com

\begin{abstract}
Purpose: Replacement iron is the main treatment for iron deficiency, but the relationship between initial intravenous (IV) dose and need for additional treatment is unclear. This study explored patterns of IV iron dosing in US clinical practice.

Methods: Patient records were obtained for adults who received IV iron for anemia between 2015 and 2017. Patients were classified into four groups: those who received $<1500 \mathrm{mg}$ and $\geq 1500 \mathrm{mg}$ IV iron and those received $\leq 1000 \mathrm{mg}$ and $>1000 \mathrm{mg}$ within 3 weeks of their first dose. The proportion of patients requiring additional IV iron after 30 days of the initial dose was evaluated.

Results: Data were obtained for 2959 patients receiving iron sucrose (44.2\%), ferric carboxymaltose injection (FCM) (25.8\%), and ferumoxytol (FM) (14.3\%). Overall, 567 patients (19\%) received $\geq 1500 \mathrm{mg}$ of IV iron and 942 (32\%) received $>1000 \mathrm{mg}$ of IV iron within the first 21 days. Mean (SD) baseline iron deficit was $1001 \mathrm{mg}$ (312). Patients who received $\geq 1500 \mathrm{mg}$ had a $32 \%$ lower probability of receiving additional IV iron than those who received $<1500 \mathrm{mg}$ (adjusted hazard ratio [HR]: 0.68 [95\% confidence interval (CI); 0.58, 0.81]) and incurred significantly fewer outpatient visits for all causes $(\mathrm{p}<0.001)$ and IV iron treatment ( $<<0.001)$. Patients who received an initial dose of $>1000 \mathrm{mg}$ had a $41 \%$ lower probability of receiving additional IV iron than those who received $\leq 1000 \mathrm{mg}$ (adjusted HR: 0.59 [95\% CI; 0.52, 0.67]) and had significantly fewer outpatient visits for all causes $(\mathrm{p}<0.001)$ and IV iron treatment $(\mathrm{p}<0.001)$. Patients receiving FCM required fewer outpatient visits than those receiving FM and other treatments, including a subgroup of patients who initially received $>1000 \mathrm{mg}$ IV iron.
\end{abstract}

Conclusion: Higher doses of IV iron within 3 weeks of first dose may reduce further IV iron treatment needs and outpatient visits. Keywords: anemia, ferric carboxymaltose injection, ferumoxytol, iron sucrose

\section{Introduction}

Iron deficiency anemia is the most prevalent form of anemia globally and can occur in patients with chronic diseases and inflammation, sometimes alongside anemia of chronic disease (ACD). ${ }^{1-3}$ Improved diets and living standards have resulted in the global burden of iron deficiency anemia decreasing over time, from $11.2 \%$ of all years of life with disability in 1990 to $8.8 \%$ in $2010 .{ }^{3}$ Anemia is now most prevalent in women of reproductive age (primarily due to menstruation) and in children, and a high prevalence of iron deficiency anemia also exists in people with gastrointestinal disorders. ${ }^{4,5}$ Symptoms of anemia include weakness and fatigue, and reduced aerobic capacity, which can impact work performance. ${ }^{3,6,7}$ If not properly treated, severe anemia can lead to hypoxia, potentially resulting in organ damage. ${ }^{8}$

Replacement iron is the mainstay therapy for iron deficiency anemia. ${ }^{5,8,9}$ Oral iron therapy is often prescribed for iron deficiency anemia, but its effectiveness is diminished and uptake from the gut is limited in patients with gastrointestinal diseases. Although blood transfusion is an effective treatment in patients with active bleeding, it only offers a temporary solution and does not address the underlying problem for iron deficiency anemia. ${ }^{5}$ Consequently, parenteral (intravenous [IV]) iron therapy is often necessary for patients with iron deficiency anemia associated with chronic diseases (often 
gastrointestinal diseases that make oral iron supplements ineffective), those with a large or sustained loss of iron, and those who cannot tolerate oral iron. ${ }^{5,8,10}$

Parenteral iron therapies that are currently available in the US vary in dose and administration schedule, and include ferric carboxymaltose (FCM), ferumoxytol (FM), iron sucrose, ferric derisomaltose, sodium ferric gluconate, and iron dextran. ${ }^{11}$

Currently, data on the association between initial IV iron dose given, durability of treatment effectiveness, and the risk of iron deficiency relapse are limited. In a previous investigation of initial IV iron dose and retreatment in patients treated with iron isomaltoside (Scandinavian NIMO study), ${ }^{12}$ an initial $>1000 \mathrm{mg}$ dose of iron isomaltoside significantly reduced the need for retreatment up to 12 months and had a higher treatment response rate compared to an initial dose of $1000 \mathrm{mg}$ or lower. ${ }^{12}$ However, the evaluation was limited to a single IV iron product in a study sample mostly composed of patients with inflammatory bowel diseases. It remains unclear if the findings are generalizable to a broader patient population receiving parenteral iron replacement therapy in US clinical practice.

The objective of this analysis was to characterize patterns of IV iron dosing in US clinical practice and examine the association between initial IV iron dose and real-world treatment effectiveness as assessed by the need for additional IV iron treatment and serum hemoglobin normalization.

\section{Methods}

\section{Patient Data Source and Eligibility}

Records data were obtained from the DRG real-world evidence (RWE) data repository US database; this database includes medical and pharmacy claims and electronic health record (EHR) data for $>300$ million patients from 2011 to the time of the study, covering approximately $98 \%$ of US health plans. Data from all sources is linked via a directmatching algorithm and then de-identified at the patient level, enabling longitudinal tracking of patients across data sources and sites of care. Linked claims data and EHRs were available for approximately 75 million patients. ${ }^{13}$

Patients were included if they were adults (aged $\geq 18$ years) who received IV iron between 1st March 2015 and 28th February 2017 and had anemia, defined as a baseline serum hemoglobin (Hgb) level below normal $(<12 \mathrm{~g} / \mathrm{dL}$ for females and $<13.5 \mathrm{~g} / \mathrm{dL}$ for males) in the 30 days before or on the date of the index (first) IV iron claim. Patients were excluded if they had received IV iron within 6 weeks of index date, were on dialysis, or if their total iron dose exceeded $4000 \mathrm{mg}$ (inclusive of index dose) over 21 days. Iron doses in excess of $4000 \mathrm{mg}$ were deemed an unlikely and unsafe amount of iron, indicating a potential error in data reporting.

\section{Analysis}

The design of the study is summarized in Figure 1. Iron deficit was estimated using the modified Ganzoni equation. ${ }^{14}$ Eligible patients were classified into four dose groups (not mutually exclusive): 1) patients with a total IV iron dose $\geq 1500 \mathrm{mg}$, 2) patients with a total IV iron dose $<1500 \mathrm{mg}$, 3) patients receiving a total IV iron dose of $>1000 \mathrm{mg}$ and 4) patients with a total IV iron dose $\leq 1000 \mathrm{mg}$, within 21 days of 1st dose. The 21-day cut-off was chosen because the US prescribing information for FM and FCM recommend completing a full course within 7-14 days; a further 7 days were allowed in order to account for potential scheduling issues arising in the real-world setting. In addition, patients were classified into three mutually exclusive treatment groups based on the index IV iron product that they received: 1) patients who received FCM; 2) patients who received FM; and 3) patients who received other IV iron products except FCM and FM.

Treatment effectiveness was assessed by the proportion of patients achieving normalized serum Hgb level within 12 months of index dose, defined as $\geq 12 \mathrm{~g} / \mathrm{dL}$ for females and $\geq 13.5 \mathrm{~g} / \mathrm{dL}$ for males. Durability of iron replacement therapy was operationally defined as the absence of additional IV iron dose 30 days after initial dose. As such, the proportion of patients receiving additional IV iron after 30 days of the initial dose was compared between dose groups of $\geq 1500 \mathrm{mg}$ vs $<1500 \mathrm{mg}$ initial IV iron dose using Cox proportional hazards regression, adjusted for comorbidities, baseline serum Hgb and baseline iron deficit level. In addition, mean number of all-cause outpatient visits and visits associated with IV iron 


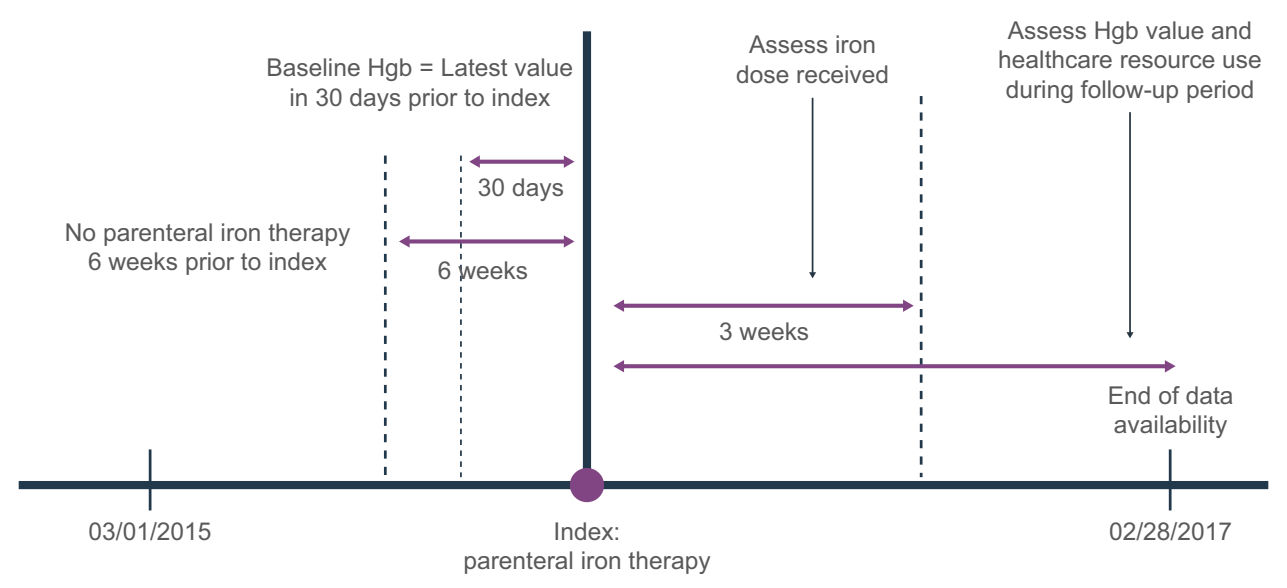

Figure I Study design.

Abbreviation: Hgb, hemoglobin.

infusion were assessed. Similar analyses were performed comparing patients who received $>1000 \mathrm{mg}$ vs $\leq 1000 \mathrm{mg}$ initial IV iron dose.

\section{Ethical Considerations}

This study was conducted in accordance with ethical guidelines outlined in the Declaration of Helsinki. The research protocol followed in this retrospective study used de-identified secondary administration claims and electronic medical records (EMRs) that were collected for routine medical care and billing purposes. These data were compliant with the Health Insurance Portability and Accountability Act (HIPAA) Privacy rule, and thus the study did not require institutional review board (IRB) review. The claims and EHR data are linked together by a HIPAA-compliant encrypted patient key generated by a third party. It was not possible to contact patients to obtain informed consent as the data were deidentified.

\section{Results}

\section{Patient Characteristics}

In total, 2959 patients were included in the analysis (Figure 2; Table 1). At baseline, 58.4\% were aged $\geq 65$ years; $68.1 \%$ were female; mean (standard deviation [SD]) baseline Hgb was $9.7 \mathrm{~g} / \mathrm{dL}$ (1.4); and median (SD) follow-up period length was 107 weeks (27.8). In total, $43 \%$ of patients (1285) had an iron deficit of $>1000 \mathrm{mg}$.

\section{Iron Treatment Received}

Iron sucrose was the most frequently used treatment type, received by 1309 patients $(44.2 \%)$, followed by FCM ( $\mathrm{n}=763$; $25.8 \%)$ and FM ( $\mathrm{n}=422 ; 14.3 \%$; Table 2$)$. Only 567 patients $(19 \%)$ received $\geq 1500 \mathrm{mg}$ of total IV iron, and 942 patients (32\%) received $>1000 \mathrm{mg}$ total IV iron within the first 21 days.

Mean (SD) index dose was $743 \mathrm{mg}$ (148) for FCM, $466 \mathrm{mg}$ (154) for FM, and $197 \mathrm{mg}$ (222) for patients receiving other IV iron products. Two-thirds (66\%) of patients treated with FCM received $\geq 1500 \mathrm{mg}$ of total IV iron during the first 21 days (Figure 3), compared with $6 \%$ of patients treated with FM and $2 \%$ of patients receiving other iron products. Approximately $73 \%$ of patients treated with FM received $>1000 \mathrm{mg}$ of total IV iron during the first 21 days (Figure 3), compared with $66 \%$ of FCM patients and $7 \%$ of patients receiving other iron products.

Patient demographics, comorbidities, and mean baseline serum Hgb were similar for those receiving $>1000 \mathrm{mg}$ and $\leq 1000 \mathrm{mg}$ of IV iron within the first 21 days. Patients receiving $\geq 1500 \mathrm{mg}$ of IV iron had a lower proportion of chronic kidney disease and congestive heart failure but a higher proportion of inflammatory bowel disease and cancer compared with patients who received $<1500 \mathrm{mg}$ of IV iron within the first 21 days. Mean (SD) baseline iron deficit for the overall study sample was $1001 \mathrm{mg} \mathrm{(312)} \mathrm{and} \mathrm{it} \mathrm{was} \mathrm{similar} \mathrm{for} \mathrm{those} \mathrm{receiving}>1000 \mathrm{mg}, \leq 1000 \mathrm{mg}, \geq 1500 \mathrm{mg}$ and $<1500 \mathrm{mg}$ 


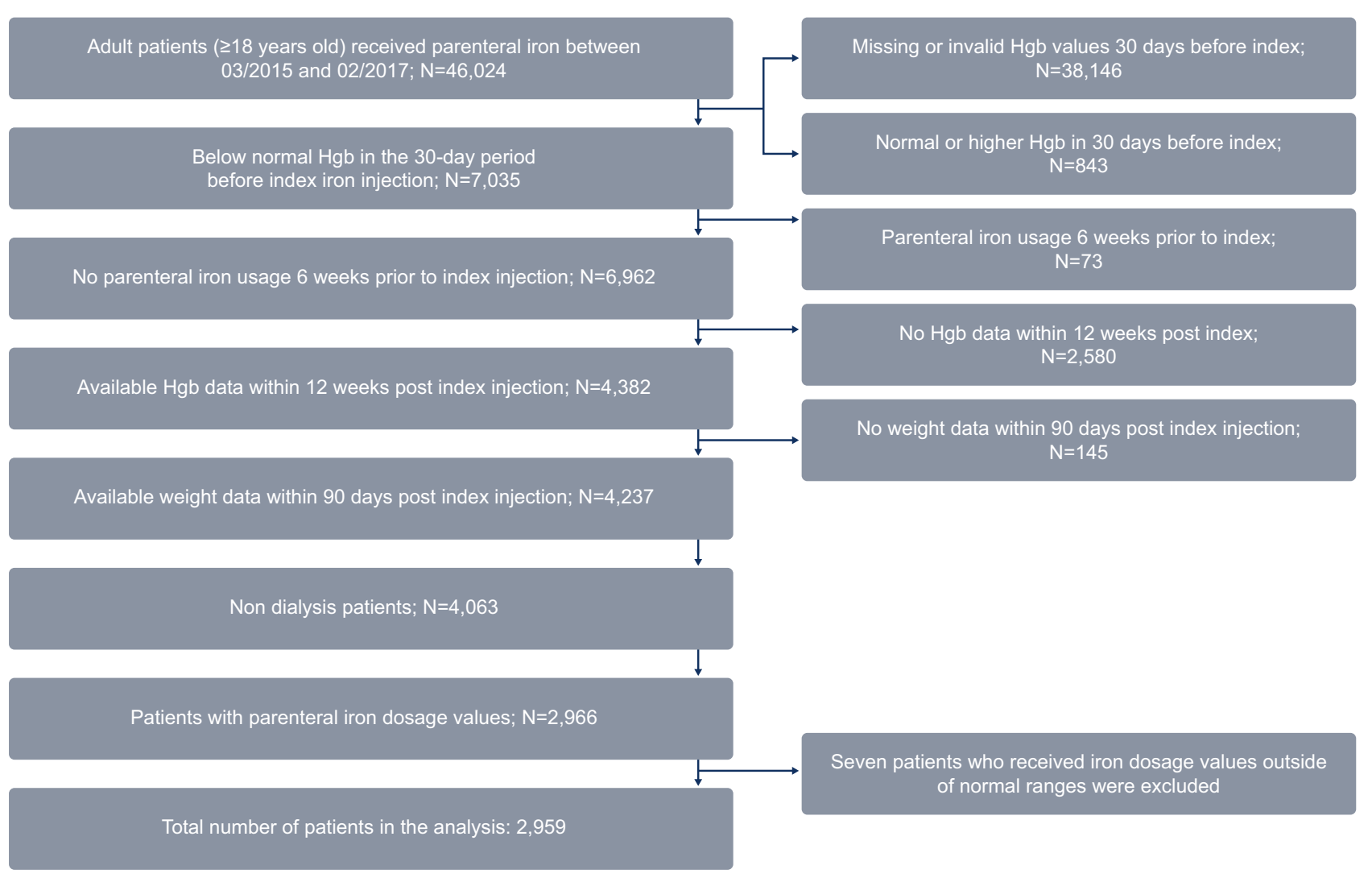

Figure 2 Patient sample attrition.

Abbreviation: Hgb, hemoglobin.

of IV iron within the first 21 days. Mean (SD) total IV iron dose was $777 \mathrm{mg}$ (558) over the first 21 days after the index dose in the overall study sample. Mean (SD) doses were $1414 \mathrm{mg}$ [405] for those receiving >1000 $\mathrm{mg}$ and $1642 \mathrm{mg}$ [368] for those receiving $\geq 1500 \mathrm{mg}$ of IV iron. For those receiving $\leq 1000 \mathrm{mg}$ and $<1500 \mathrm{mg}$ of IV iron, the mean (SD) doses were $479 \mathrm{mg}(320)$ and $572 \mathrm{mg}$ (366), respectively, over the first 21 days.

\section{Serum Hemoglobin Normalization and Further IV Iron Treatment Requirements}

Within 12 months of the index dose, the proportion of patients achieving normalized serum Hgb was highest for those receiving $\geq 1500 \mathrm{mg}(62 \%)$, followed by patients receiving $>1000 \mathrm{mg}(56 \%)$ as compared to those receiving $<1500 \mathrm{mg}(45 \%)$ and $\leq 1000 \mathrm{mg}(44 \%)$ over the first 21 days $(\mathrm{p}<0.001$; Figure 4). The mean (standard error [SE]) number of all-cause outpatient visits and the mean (SE) number of outpatient visits for IV iron treatment were significantly lower in patients receiving $\geq 1500 \mathrm{mg}$ than $<1500 \mathrm{mg}$ iron (all-cause visits: 10 [0.59] and 13 [0.33], respectively [p $<0.001$ ]; IV iron treatment visits: 2 [0.08] and 4 [0.06], respectively [p $<0.001]$; Figure 4). Similarly, the mean (SE) number of all-cause outpatient visits and the mean (SE) number of outpatient visits for IV iron treatment was significantly lower in patients receiving $>1000 \mathrm{mg}$ than $\leq 1000 \mathrm{mg}$ iron required significantly fewer outpatient visits (all-cause visits: 11 [0.46] vs 14 [0.37], respectively, $p<$ 0.001; IV iron treatment visits: 3 [0.08] vs 4 [0.07], respectively, $p<0.001$; Figure 4). During the 12-month period after index IV dose, the proportion of patients requiring $\geq 3$ IV iron infusions was lowest among patients who received an initial dose of $\geq 1500 \mathrm{mg}$ during the first 21 days (39\%), followed by patients who received an initial dose of $>1000 \mathrm{mg}$ (43\%), patients who received $<1500 \mathrm{mg}(56 \%)$ and those who received $<1000 \mathrm{mg}(57 \%)$ over the first 21 days.

After adjusting for comorbidities, baseline serum $\mathrm{Hgb}$ level and baseline iron deficit level, patients who received an initial dose of $\geq 1500 \mathrm{mg}$ had a $32 \%$ lower probability of receiving additional IV iron 30 days after index IV iron dose than those who received $<1500 \mathrm{mg}$ (adjusted hazard ratio [HR]: 0.68 [95\% confidence interval (CI); 0.58, 0.81]; Figure 4) during the entire study follow-up period. For those who received an initial dose of $>1000 \mathrm{mg}$ during the 
Table I Cohort Demographics and Characteristics

\begin{tabular}{|c|c|c|c|c|c|}
\hline & $\begin{array}{c}\text { All } \\
\text { Patients }\end{array}$ & $\begin{array}{l}\text { Received } \\
>1000 \mathrm{mg}\end{array}$ & $\begin{array}{l}\text { Received } \\
\leq 1000 \mathrm{mg}\end{array}$ & $\begin{array}{l}\text { Received } \\
\geq 1500 \mathrm{mg}\end{array}$ & $\begin{array}{l}\text { Received } \\
<1500 \mathrm{mg}\end{array}$ \\
\hline Total, n (\%) & 2959 & $942(31.8)$ & $2017(68.2)$ & $567(19.2)$ & $2392(80.8)$ \\
\hline Female gender, n (\%) & $2014(68.1)$ & $620(65.8)$ & $1394(69.1)$ & $375(66.1)$ & $1639(68.5)$ \\
\hline \multicolumn{6}{|l|}{ Age, n (\%) } \\
\hline $18-44$ & $44 \mid(14.9)$ & $118(12.5)$ & $323(16.0)$ & $80(14.1)$ & $36 I(15.1)$ \\
\hline $45-54$ & $351(11.8)$ & $107(\mathrm{II} .4)$ & $244(12.1)$ & $79(13.9)$ & $272(11.4)$ \\
\hline $55-64$ & $438(14.8)$ & $125(13.3)$ & $313(15.5)$ & $79(13.9)$ & $359(15.0)$ \\
\hline$\geq 65$ & $1729(58.4)$ & $592(62.8)$ & II 37 (56.4) & $329(58.0)$ & $1400(58.5)$ \\
\hline \multicolumn{6}{|l|}{ Comorbidities, n (\%) } \\
\hline Abnormal uterine bleeding & $117(4.0)$ & $37(3.9)$ & $80(4.0)$ & $24(4.2)$ & $93(3.9)$ \\
\hline CKD (non-dialysis) & $840(28.4)$ & $285(30.3)$ & $555(27.5)$ & $120(2 \mid .2)$ & $720(30.1)$ \\
\hline $\mathrm{CHF}$ & $524(17.7)$ & $160(17.0)$ & $364(18.0)$ & $69(12.2)$ & $455(19.0)$ \\
\hline IBD & $62(2.1)$ & $27(2.9)$ & $35(1.7)$ & $18(3.2)$ & $44(1.8)$ \\
\hline Post-partum anemia & $\mathrm{I}(0.0)$ & - & $\mathrm{I}(0.0)$ & - & I $(0.0)$ \\
\hline Cancer & $667(22.5)$ & $233(24.7)$ & $434(2 \mid .5)$ & $150(26.5)$ & $517(21.6)$ \\
\hline \multicolumn{6}{|l|}{ Prescription oral therapy, n (\%) } \\
\hline 3 months pre-index & 7I (2.4) & $29(3.1)$ & $42(2.1)$ & $22(3.9)$ & $49(2.1)$ \\
\hline 3 months post-index & $37(1.3)$ & $4(0.4)$ & $33(1.6)$ & $\mathrm{I}(0.0)$ & $36(1.5)$ \\
\hline 3 months pre- and post-index & $41(1.4)$ & II (I.2) & $30(1.5)$ & $7(1.2)$ & $34(1.4)$ \\
\hline Mean weight, kg (SD) & $83(23.7)$ & $84(23.5)$ & $82(23.8)$ & $85(23.9)$ & $82(23.6)$ \\
\hline Mean baseline Hgb, g/dL (SD) & $9.66(1.43)$ & $9.72(1.40)$ & $9.64(1.45)$ & $9.79(1.42)$ & $9.63(1.44)$ \\
\hline $\begin{array}{l}\text { Mean iron deficit per modified Ganzoni, mg } \\
\text { (SD) }\end{array}$ & $100 \mid(3 \mid 2)$ & $1007(320)$ & $998(308)$ & $998(315)$ & $100 I(3 I I)$ \\
\hline $\begin{array}{l}\text { Mean IV iron dose received in first } 3 \\
\text { weeks, } \mathrm{mg}(\mathrm{SD})\end{array}$ & $777(558)$ & $14 \mid 4$ (405) & $479(320)$ & $1642(368)$ & $572(366)$ \\
\hline
\end{tabular}

Abbreviations: CHF, chronic heart failure; CKD, chronic kidney disease; Hgb, hemoglobin; IBD, inflammatory bowel disease; IV, intravenous; SD, standard deviation.

Table 2 Type of IV Iron Treatments Received by Cohort

\begin{tabular}{|l|c|c|}
\hline \multirow{2}{*}{ IV Iron Treatment Received } & \multicolumn{2}{|c|}{ Patients } \\
\cline { 2 - 3 } & N & $\%$ \\
\hline Iron sucrose & 1309 & 44.2 \\
\hline FCM & 763 & 25.8 \\
\hline FM & 422 & 14.3 \\
\hline Sodium ferric gluconate & 108 & 3.6 \\
\hline Iron dextran & 357 & 12.1 \\
\hline
\end{tabular}

Abbreviations: FCM, ferric carboxymaltose; FM, ferumoxytol; IV, intravenous. 
A

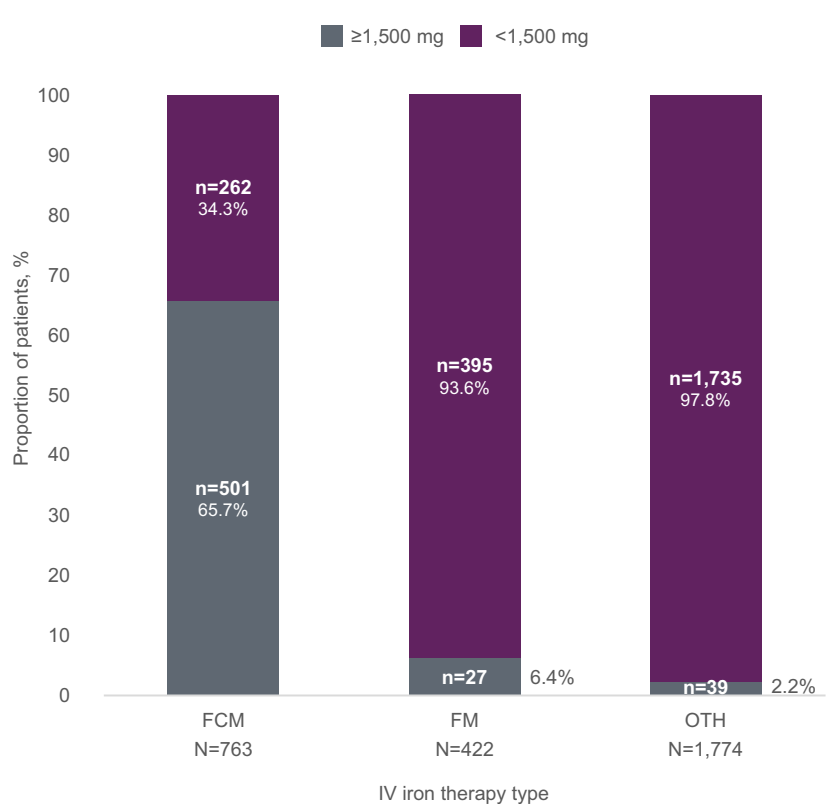

B

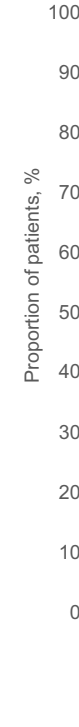

Patients with IV iron dose $\leq 1,000 \mathrm{mg}$ or $>1,000 \mathrm{mg}$

$$
\geq 1,000 \mathrm{mg} \quad \leq 1,000 \mathrm{mg}
$$

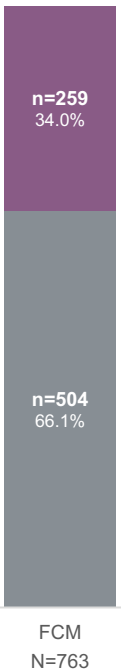

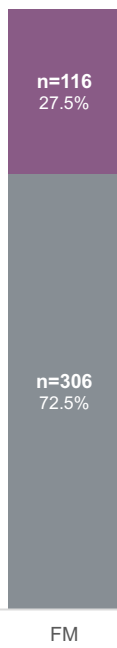

$\mathrm{N}=422$

IV iron therapy type

Figure 3 Proportion of patients receiving IV iron products within 21 days of index by dose $(\mathbf{A})<1500 \mathrm{mg}$ and $\geq 1500 \mathrm{mg}$ and $(\mathbf{B}) \leq 1000 \mathrm{mg}$ and $>1000 \mathrm{mg}$. Abbreviations: FCM, ferric carboxymaltose; FM, ferumoxytol; IV, intravenous; OTH, other.

A Mean all-cause outpatient visits

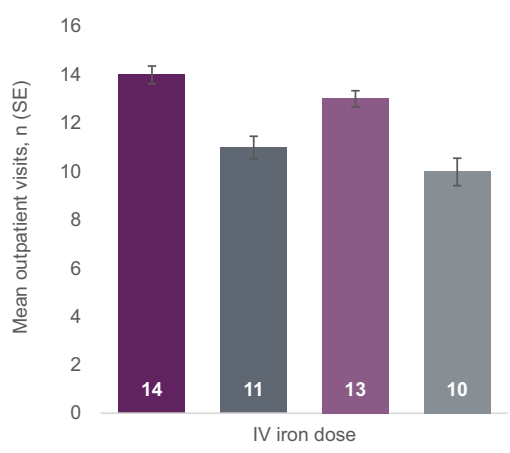

B

Mean outpatient visits for IV iron treatment

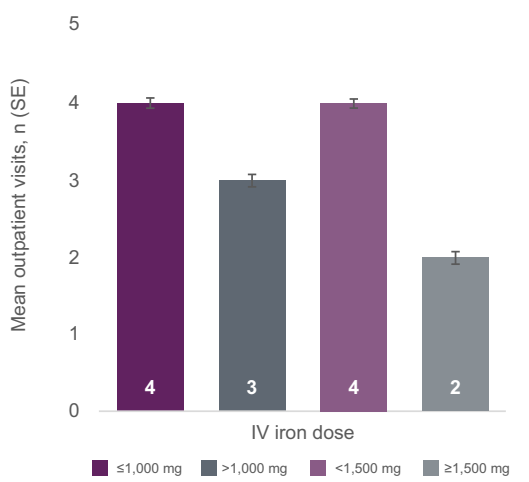

C Proportion of patients achieving normalized serum Hgb

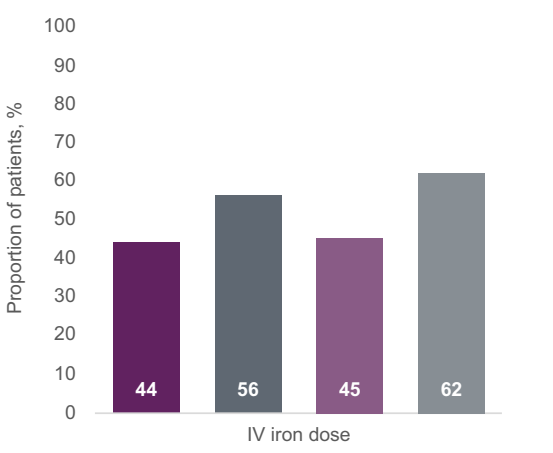

Figure 4 Outcomes in patients receiving an initial dose of IV iron. (A) Mean all-cause outpatient visits, (B) mean outpatients visits for IV iron treatment and (C) proportion of patients achieving normalized serum Hgb.

Abbreviations: IV, intravenous; SE, standard error.

first 21 days after index IV iron dose, the probability of receiving additional IV iron 30 days after index IV iron dose was $41 \%$ lower than for those who received $\leq 1000 \mathrm{mg}$ (adjusted HR: 0.59 [95\% CI; 0.52, 0.67]; Figure 5).

Among the three IV iron product groups, FCM had the highest proportion of patients achieving normal serum Hgb level (61\%) and the lowest proportion of patients requiring $\geq 3$ IV iron infusions within 12 months of index IV iron dose (27\%) (Figure 6). The mean number of all-cause outpatient visits and visits related to IV infusion within 12 months of treatment was highest among patients treated with "other" IV iron therapies, and the lowest proportion was of those treated with FCM (Figure 6). Treatment group differences were similar in the subgroup of patients with a $>1000 \mathrm{mg}$ deficit. 

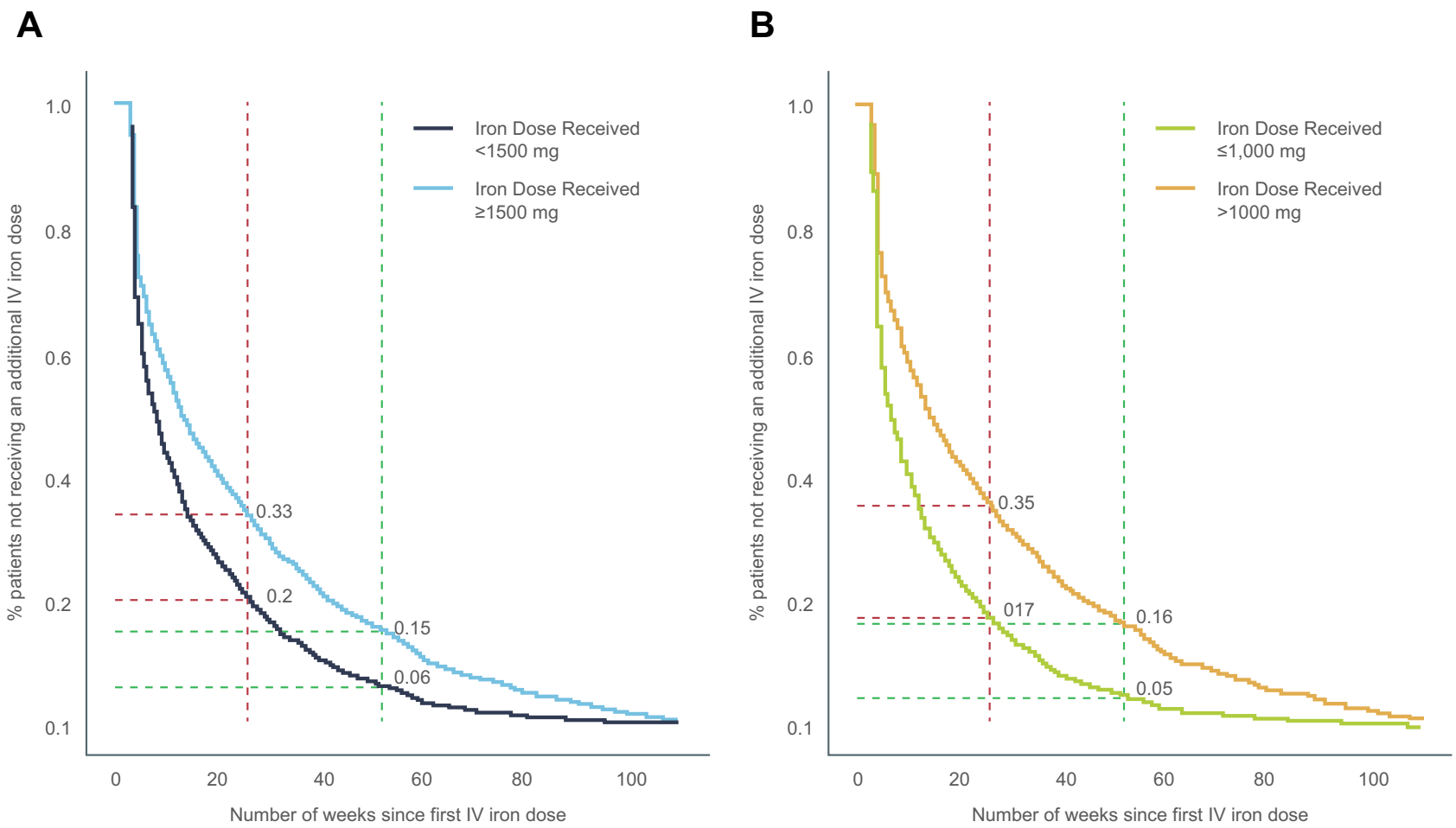

Figure 5 Probability of receiving an additional IV iron dose during study follow-up period in patients receiving $(\mathbf{A})<1500 \mathrm{mg}$ and $\geq 1500 \mathrm{mg}$ and $(\mathbf{B}) \leq 1000 \mathrm{mg}$ and $>1000 \mathrm{mg}$.

Abbreviation: IV, intravenous.

\section{Discussion}

This analysis showed that high doses of IV iron within three weeks of first dose may offer an effective treatment option that is convenient for patients with iron deficiency anemia in need of parenteral therapy. By reducing the need to return for further treatment, high iron doses may minimize the risk of treatment ineffectiveness due to patient non-compliance and reduce healthcare resource utilization in patients with iron deficiency anemia receiving IV iron therapy.

Results of these data suggest that underdosing is common in real-world practice and it should be a consideration when initiating treatment. Despite a mean iron deficit of $1001 \mathrm{mg}$ in the study sample, the mean IV iron dose received during the 3 weeks from index was only $777 \mathrm{mg}$. Mean iron deficit levels did not differ across dose groups, corroborating previous findings that baseline iron deficits are often not considered when choosing between IV iron products and determining IV iron dose for repletion in real-world practice. ${ }^{15}$ Moreover, our data suggested that many patients did not receive IV iron consistent with a product's dosing recommendations. For example, during the first 21 days of treatment, our study showed that one in three patients treated with FCM received total cumulative IV iron dose lower than the recommended dose of $1500 \mathrm{mg}$ of total IV iron. Similarly, approximately 1 in 4 of patients treated with FM received IV iron dose lower than the recommended cumulative total dose of $1020 \mathrm{mg}$. Although the reason for underdosing is unclear, possible barriers to adequate dosing might be poor follow-up or patients not returning to clinic after their first dose of IV iron.

At the time of this study, FCM and FM were the only IV iron products available on the US market providing a total cumulative dose $>1000 \mathrm{mg}$ in an initial course of IV iron therapy. In this study, treatment with IV iron of $\geq 1500 \mathrm{mg}$ and $>1000 \mathrm{mg}$ was associated with significant reduction in the likelihood of additional IV iron treatment after 30 days. Treatment with FCM was also associated with lowest number of outpatient visits and the highest likelihood of normalized $\mathrm{Hgb}$ recovery among the three IV product groups, across both the overall cohort and the subgroup of patients with an iron deficit of $>1000 \mathrm{mg}$. This indicates that the clinical benefit of high-dose IV iron is not only limited to patients with a high estimated iron deficit; rather, full replenishment of iron with a high dose IV product in the first 3 weeks of 
A

Patients requiring $\geq 3$ injections within 12 months

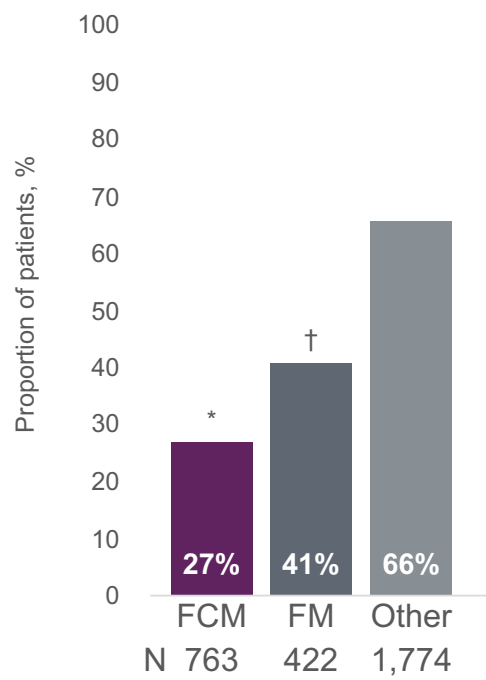

All patients

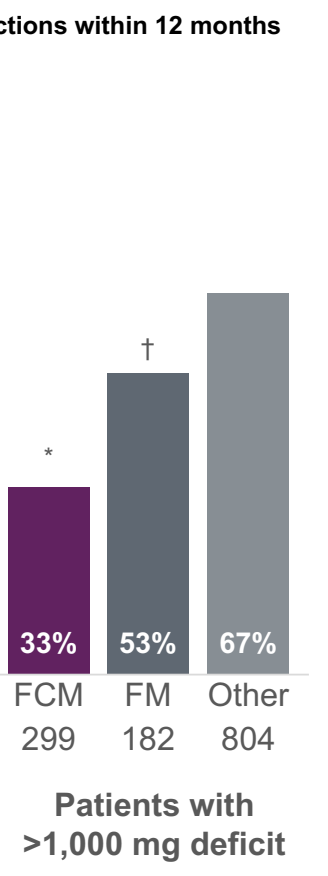

Patients with

$>1,000 \mathrm{mg}$ deficit
B

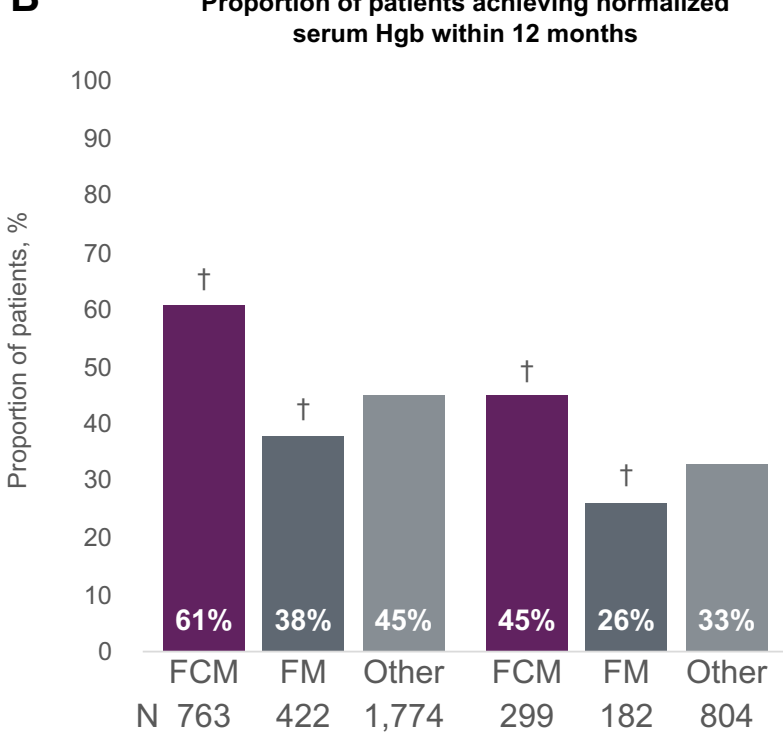

C Mean all-cause outpatient visits

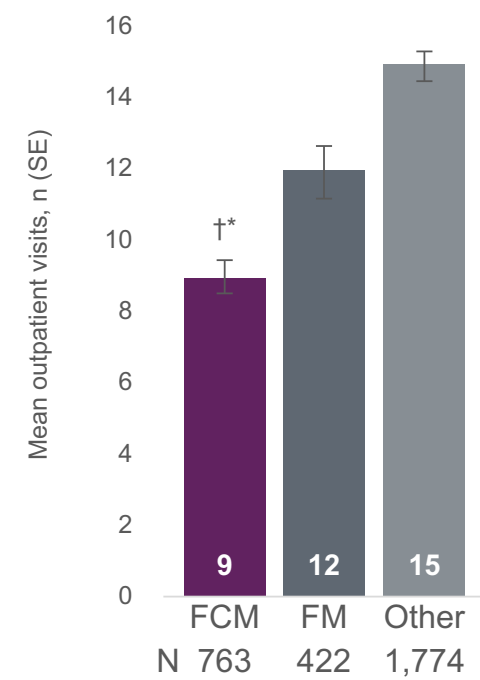

All patients

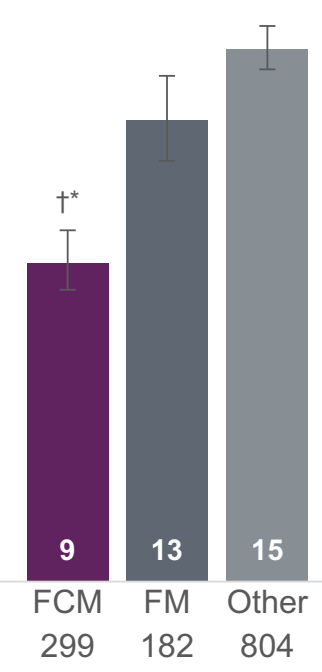

Patients with $>1,000$ mg deficit
All patients

Patients with $>1,000 \mathrm{mg}$ deficit
Dean outpatient visits for iron infusion



Figure 6 Post-infusion resource use by treatment type. (A) Patients requiring $\geq 3$ injections within 12 months, (B) proportion of patients achieving normalized serum Hgb within 12 months, (C) mean all-cause outpatient visits, (D) mean outpatient visits for iron infusion.

Notes: *Statistically significant difference vs FM $(p<0.001)$; ${ }^{\dagger}$ statistically significant difference vs other $(p<0.001)$.

Abbreviations: FCM, ferric carboxymaltose; FM, ferumoxytol; Hgb, hemoglobin; IV, intravenous.

treatment appears to be important in reducing the clinical and economic burden of patients with iron deficiency anemia, irrespective of deficit. The mean number of infusion-related office visits in the low-dose IV iron group was highest and doubled that of patients treated with FCM and FM, but the proportion of patients achieving normalized serum Hgb was lowest for the low-dose IV iron group. These results suggest that giving low dose IV iron more frequently may be ineffective to provide sufficient iron repletion. 
The study has several limitations. First, the study was a retrospective analysis of claims and EMR data from an open network. Claims data are often adjudicated on an ongoing basis. Healthcare services provided by out-of-network providers may not be captured by the database, which could lead to imprecision in the healthcare resource utilization results. Additionally, use of concomitant over-the-counter oral iron replacement medications was not captured by the database. We cannot completely rule out possible confounding from patient self-administered oral iron supplementation. Because the study required serum Hgb data, patients who did not have complete Hgb data recorded in EMRs were excluded, which could limit the generalizability of the study findings. A higher proportion of cancer patients and lower proportions of patients having non-dialysis dependent chronic kidney disease and congestive heart failure were observed among patients receiving $\geq 1500 \mathrm{mg}$ dose group than the $<1500 \mathrm{mg}$ group. Future studies are needed to determine the effect of these comorbidities on study results. Because ferritin data were limited in the database, we were unable to assess iron stores to further understand the durability of iron repletion. Ferric derisomaltose was recently approved in the US and its data were not available at the time of the study. Future studies including data from ferric derisomaltose will provide a more comprehensive assessment on the effect of high dose IV iron on clinical and economic burden of iron deficiency anemia among US patients. A longer-term assessment could provide better insights into long-term patient outcomes.

\section{Conclusion}

In a real-world US setting, initial treatment with higher total dose of IV iron was associated with improved serum hemoglobin levels, reduced need for further iron treatment and lower healthcare resource utilization.

\section{Funding}

This research was funded by Daiichi Sankyo Inc.

\section{Disclosure}

CL, IB, and SK were employees of Clarivate, a healthcare analytics consultancy, at the time of the study. WJK is an employee of Daiichi Sankyo Inc. RVB was a consultant to Daiichi Sankyo, Amgen, Bristol Myers Squibb, AMAG, SecuraBio, and was on the speaker's bureau of Rigel and Celgene during the time of this study. The authors report no other conflicts of interest in this work.

\section{References}

1. Camaschella C. New insights into iron deficiency and iron deficiency anemia. Blood Rev. 2017;31(4):225-233. doi:10.1016/j. blre.2017.02.004

2. Poggiali E, Migone De Amicis M, Motta I. Anemia of chronic disease: a unique defect of iron recycling for many different chronic diseases. Eur $J$ Intern Med. 2014;25(1):12-17. doi:10.1016/j.ejim.2013.07.011

3. Kassebaum NJ, Jasrasaria R, Naghavi M, et al. A systematic analysis of global anemia burden from 1990 to 2010. Blood. 2014;123(5):615-624. doi:10.1182/blood-2013-06-508325

4. World Health Organization (WHO). The global prevalence of anaemia in 2011; 2015. Available from: https://apps.who.int/iris/handle/10665/ 177094. Accessed February 18, 2022.

5. Jimenez K, Kulnigg-Dabsch S, Gasche C. Management of iron deficiency anemia. Gastroenterol Hepatol (N Y). 2015;11(4):241-250.

6. Haas JD, Brownlie T. Iron deficiency and reduced work capacity: a critical review of the research to determine a causal relationship. $J$ Nutr. 2001;131(2s-2):676S-88S; discussion 88S-90S. doi:10.1093/jn/131.2.676S

7. Lasch KF, Evans CJ, Schatell D. A qualitative analysis of patient-reported symptoms of anemia. Nephrol Nurs J. 2009;36(6):621-4, 31-2; quiz 633.

8. Johnson-Wimbley TD, Graham DY. Diagnosis and management of iron deficiency anemia in the 21st century. Therap Adv Gastroenterol. 2011;4 (3):177-184. doi:10.1177/1756283X11398736

9. Goddard AF, James MW, McIntyre AS, Scott BB. Guidelines for the management of iron deficiency anaemia. Gut. 2011;60(10):1309. doi:10.1136/ gut.2010.228874

10. De Franceschi L, Iolascon A, Taher A, Cappellini MD. Clinical management of iron deficiency anemia in adults: systemic review on advances in diagnosis and treatment. Eur J Intern Med. 2017;42:16-23. doi:10.1016/j.ejim.2017.04.018

11. Auerbach M, Macdougall I. The available intravenous iron formulations: history, efficacy, and toxicology. Hemodial Int. 2017;21(Suppl 1):S83s92. doi:10.1111/hdi.12560

12. Frigstad SO, Haaber A, Bajor A, et al. The NIMO Scandinavian study: a prospective observational study of iron isomaltoside treatment in patients with iron deficiency. Gastroenterol Res Pract. 2017;2017:4585164. doi:10.1155/2017/4585164 
13. Decision Resources Group (DRG). Real world evidence US data repository; 2015. Available from: https://clarivate.com/products/real-world-data/. Accessed February 18, 2022.

14. Koch TA, Myers J, Goodnough LT. Intravenous iron therapy in patients with iron deficiency anemia: dosing considerations. Anemia. 2015;2015:763576. doi:10.1155/2015/763576

15. LaVallee C, Cronin P, Bansal I, Kwong WJ, Boccia RV. Effectiveness of parenteral iron therapy in the real-world setting: a retrospective analysis. J Clin Haematol. 2020;1(1).

\section{Publish your work in this journal}

The Journal of Blood Medicine is an international, peer-reviewed, open access, online journal publishing laboratory, experimental and clinical aspects of all aspect pertaining to blood based medicine including but not limited to: Transfusion Medicine; Blood collection, Donor issues, Transmittable diseases, and Blood banking logistics; Immunohematology; Artificial and alternative blood based therapeutics; Hematology; Biotechnology/nanotechnology of blood related medicine; Legal aspects of blood medicine; Historical perspectives. The manuscript management system is completely online and includes a very quick and fair peer-review system. Visit http://www.dovepress.com/testimonials.php to read real quotes from published authors.

Submit your manuscript here: http://www.dovepress.com/journal-of-blood-medicine-journal 